\title{
Ethical Decision-Making in Cultural Context: Implications for Professional Practice
}

\author{
Prof Nhlanhla Mkhize \\ Head of School: Applied Human Sciences, University of KwaZulu-Natal \\ Mkhize@ukzn.ac.za \\ Mrs Sibonsile Bonnie Mathe \\ Lecturer: Social Work, University of KwaZulu-Natal \\ Mathes12@ukzn.ac.za \\ Mrs Nontobeko Buthelezi \\ Lecturer: Psychology, University of KwaZulu-Natal \\ Buthelezin@ukzn.ac.za
}

Doi:10.5901/mjss.2014.v5n23p2413

\begin{abstract}
Professional codes of ethics are generally premised on self-contained individualism, the view that individuals exist independently of culture, history and time. In this article we argue that, to understand ethical decision-making in indigenous societies, it is important to come to terms with the "social reality" of the people in question. Social reality constitutes the manner in which human interactions are understood, roles defined, and transactions enacted. Due to differences in social realities, practitioners encounter multiple and overlapping health-care systems among indigenous peoples. The ethical implications of practising social work and psychology in such contexts are discussed. We argue that self-contained individualism is problematic in traditional African settings where selfhood is not only communally defined but is also distributed in space and time. Using professional codes of ethics in Social Work and Psychology as our points of departure and with reference to concepts such as professional boundaries, self-determination, and informed consent, the ethical implications of the tensions between communal and individualistic conceptions of selves are discussed. Implications for clinical practice are highlighted.
\end{abstract}

Keywords: Professional Ethics, Indigenous Societies, African-centred Practice

\section{Background}

The democratic ideals of the post-colonial and post-apartheid Africa continue to set the agenda for the creation of multicultural societies which respect diversity, promote social justice and equity, and maintain social permeable frames of reference. In South Africa for instance, social work and psychology are the professions that have been identified as vehicles for social transformation and healing. Their relevance is dependent on their knowledge base, skills, practice, values and ethics reflecting this transformative agenda. Regrettably, their current professional codes of ethics continue to be dominated by the epistemological paradigms of the Western colonial conquerors. It is against this background that the ethical implication of practicing social work and psychology with indigenous societies is discussed in this article.

According to the National Association of Social Workers (NASW) of (1996) and the Health Professions Council of South Africa (HPCSA) form 223 (2004), professional ethics form the core in the practice of social workers and psychologists. NASW further claims that the Code is relevant to all social workers and social work students, regardless of their professional functions, the settings in which they work, or the populations they serve. Healy (2007) adds that social work values and ethics have often been held out as unifying features of the profession. We view this universality and homogenizing discourse as problematic. Particular since the existing educational structures and policies guiding the training of social workers and psychologists were conceived during the European colonial period. Such education is largely dominated by Western culture (Tedla, 2005).

The existing knowledge base for social work and psychology has emerged from epistemologies that are an expression of European historical and cultural development (Graham, 1999). Similarly, Payne and Askeland (2008) have describe social work as a product of modernism in Western states, and that while it has always been international, it has 
increasingly become so. Homogenizing professional ethics in different cultural context is a form of oppression and discrimination. The values must be of the people, for the people, and by the people (Larue, 1998). Askeland and Payne (2006) assert that, homogenization leads to a dominant culture similarly overpowering other cultures, but by other means, primarily through cultural oppression. Skutnabb-Kangas (1991) cited in Askeland and Payne (2006) warned that while physical colonialism has declined, linguistic and cultural colonialism has taken over. Social practices such as social work and institutions such as education are part of homogenizing processes allowing culture to be used in a post-colonial environment to dominate (ibid). We argue that the idea of universal knowledge conflicts with the idea that different cultures have different ways of understanding the world. An obvious observation is that Western human service professions exert its influence in the developing world through the individualistic methodologies of helping (Caragata and Sanchez, 2002 cited in Moldovan \& Moyo, 2007) while helping methodologies for Africans emphasise collectivism.

Increased movement of social workers and transmission or exchange of practices and ideas in social work, it could be argued, lead to an increased homogeneity of the profession between regions and countries (Hugman, 2010). Painter, Terre Blanche and Henderson (2006) write about how homogeneity of psychology was done by playing the politics of scientific neutrality. Even if we accept the idea of a common core to social work and psychology, it may still be argued that the emphasis in different countries is so diverse that we should reject the idea of integration that is contained in the concept of 'global' (Hugman, 2010 and Painter et al, 2006). Over the past 30 years social work writers have been trying to raise awareness of the dominance of Western influences on social work and have been stressing the need for social work in the developing world to free itself from the 'in-built assumptions and cultural biases of first world theories and models of practice' and to develop indigenous education and practice (Brigham, 1982; Campfen, 1988; Hammoud, 1988; Ife, 2000; Mandal, 1989; Midgley, 1981; Mupedziswa, 1997; Osei-Hwedie, 1995; Ow, 1991; Payne, 1990; Resnick, 1980; Rosenman, 1980; Shawkey, 1972; Tsang et al., 2000; Walton \& Abo El Nasr, 1988 cited in Payne \& Askeland, 2008).

Many social workers across the world are becoming ever more vocal about the forces of 'professional imperialism', particularly in the developing world, while others question the universal applicability and superiority of professional social work values (Payne \& Askeland, 2008). In South African Psychology, critical agendas have appeared in various forms and locations since the early 1980s (Painter et al, 2006). Similarly, the African-centered worldview has challenged social work to expand its philosophical and intellectual base to embrace humanity; to release the domination of the Eurocentric worldview over the psyche of African peoples; and to open the way for the transformation, creativity, and unlimited potential that is embedded within authenticity (Graham, 2009; Schiel, 1994; Dei, 1994; Asante, 1988). Cultures are a complex of connections between 'general human development and a particular way of life and between both and the works and practices of art and intelligence' (Askeland and Payne, 2006). Cultural diversity is needed just as much as biodiversity (ibid). Similarly, a larger pool of cultures and knowledges may make it possible to deal with a wider range of human situations (ibid).

In 2000, as an attempt to become an international, universal profession; social work through it International Federation of Social Workers (IFSW) and International Association of Schools of Social Work's (IASSW) adopted an international definition of social work.

\begin{abstract}
"The social work profession promotes social change, problem solving in human relationships and the empowerment and liberation of people to enhance well-being. Utilizing theories of human behaviour and social systems, social work intervenes at the points where people interact with their environments. Principles of human rights and social justice are fundamental to social work" (IFSW, 2000).
\end{abstract}

IFSW and IASSW view this definition as had captured many of the facets of what is seen to be 'social work' around much of the world (Askeland \& Payne, 2006). Given the commitment expressed by the social work community through the values and ethics of social justice and human rights as reflected in this international definition, the question of contextspecific social work cannot be ignored. This means among other things 'recognizing diversity' - implying that social workers should recognize and respect the ethnic and cultural diversity of the societies in which they practise, taking account of individual, family, group and community differences (Solas, 2008). Moreover, the value base of social work emanates from a belief in the inherent worth and dignity of all people and the repudiation of all forms of negative discrimination (Graham, 1999, Banks, 1995; Schiele, 1994). These are honourable principles that cannot be achieved, however, when the supremacy of the social work knowledge base supports 'Professional Ethics' that are inclined towards Western culture and worse, are assumed to be universally applicable. Yip (2004) cited in Hugman (2008), argues that claims for an ethics that is applicable to social work in all contexts are both theoretically and practically inappropriate. Social work is so context bound that Tsang and Yan (2001) stated that 'any universal claim regarding the nature, purpose and method of the profession must be regarded with caution (cited in Hugman, 2008). The pertinent question for 
countries like South Africa where indigenous societies are the majority is: how can social work interventions be a vehicle for social transformation and healing when social work itself is an expression of the dominant culture and worldview?

\section{Ethical Implications of Practicing Social Work and Psychology in Indigenous Societies}

Social work and psychology are professions that vary enormously by historical, geographical, and institutional contexts (Healy, 2005:1, Painter et al, 2006). Practitioners from these professions in everyday practice encounter different cultures with values that conflict with their own and must struggle with the practical question: 'when is different just different and when is different wrong?' (Donaldson, 1996 cited in Healy, 1997). 'Good' social work practice is inevitably contextual (Fook, 2002; Healy, 2005 cited in Lyngstad, 2012). To have some knowledge and understanding of local conditions is very useful and sometimes a must if we want to address problems and design helping methods in an adequate way.

The ethical dilemmas arise frequently in social work, especially in situations regarding equality claims for women; children; ethnic, religious and sexual minorities; or involving tensions over individualism against the claims of the group or community (also known as communalism) (Healy, 1995). The source of such dilemmas is sometimes a contradiction between 'universal' values, community values and predominant attitudes in the community. The controversies and tension originating from one's loyalty to local institutional environments, with their specific understandings, values and culture on the one side and internalized principles according to universal human right principles and social justice values that the social workers have acquired from their social work education on the other, are challenging and demanding and need a profound amount of reflection from the social worker (Hugman, Moosa \& Moyo, 2010). This dilemma reflects a major debate about the universality vs the particularity of values; individualistic conception of self vs communal conceptions; and international vs indigenization of human service practices. According to Wong (2002) cited in Gray (2005), Indigenization challenges universal knowledge and the cultural hegemony of dominant discourses globally and locally. Vlaenderem and Neves (2004) asserts that emancipatory critical psychology should pay attention to concepts of participation, empowerment and capacity building. Given the international social work literature on cultural diversity and culturally sensitive social work practice that privileges local cultures; values and philosophies that underlie practice must be influenced by local factors including local cultures (Osei-Hwedie, 2001). In psychology, the importance of situated local or everyday knowledge as the guiding force for local community behaviour which helps in shaping their mental map and alerts that such knowledge is not static but dynamic and functional, has been highlighted. Elevating social work values to universal rules puts social workers in a position akin to many so-called liberals who claim to respect people's way of life provided these people abide by their rules (Bar-On, 1998 cited by Gray, 2005).

\section{Professional Boundaries and Dual Relationship}

The NASW code of ethics (1996) included a provision on dual relationships. Dual relationships are defined as relationships occurring when social workers relate to clients in more than one relationship whether; professional, business, personal or sexual (Congress and McAuliffe, 2006). The primary and appropriate relationship with a client is professional. Almost all social work practitioners and social work educators concur that sexual relationships with current clients or students are unethical (ibid). The South African Council for Social Service Professions (SACSSP) further prohibit sexual intimacies with former clients and client's relatives. This prohibition contradicts with the profession's assumption of human development as being lifelong which view people as capable of growth and change (Berk, 1998). Social workers who believe that dual relationships with former clients should not be avoided have argued that the code's provision implies that once a client always a client (Congress and McAuliffe, 2006). Also, it has been argued that some social activities with a client such as attending a graduation or wedding may be therapeutic for the client, especially when treatment goals have included educational and/or interpersonal milestones (ibid).

A more general concern has been that this code provision about dual relationships reflects an Anglo bias and that it does not support culturally sensitive practice, a major aim of current social work practice (Dei, 1994). It has been suggested that developing a personal relationship may be a prerequisite in developing a therapeutic relationship (Congress, 1990). This requirement for a distinct professional relationship is of particular concern in communities such as the Zulu communities of South Africa. In these communities, the role and function of the wider kin-based groups such as the lineage and clan groupings are of greater significance. Formal or informal professional introductions are better forged or negotiated through kinship ties. In fact establishment of kinship lineages or non-lineages are a starting point of conversations in Zulu communities. In practice, initial introductions before the purpose of the visit or contact is discussed, are marked by all parties' identification of their maternal and paternal lineages which generally include brief family histories, clan names and praise names. This is how Egan's professional rapport is established in such African 
communities (Nelson, 2007). The fact that the claim of common ancestry may be mystical or putative among these groupings, are of no significance to them (Congress and McAuliffe, 2006). Such common ancestorship symbolized the social unity and identity of the members to the effect that the kin group takes on the role of the major functions in the society (ibid).

The indigenous community value collective identity instead of individualistic identity. African ethics are communistic in nature. Within the cosmological perspective of the African-centered worldview, all elements of the universe-people, animals, and inanimate objects-are viewed as interconnected. Because they are dependent on each other, they are, in essence, considered as one (Mbiti, 1970; Nobles, 1985 cited in Graham, 1999). For Akbar (1976) cited in Graham (1999), the unity of the African cosmos is like a spider web; its least element cannot be touched without making the whole vibrate. These relationships provide individuals with a sense of purpose and connection with families and community. This is so evident in the African proverb that says: 'I am because we are, and since we are therefore I am' (Mbiti, 1969). This collective responsibility is restrained by some of the universal fundamental principles that underlie professional codes. For example attending a funeral of a deceased client might be construed as infringement of privacy if other members of the public make a link between the practitioner and the deceased client. In a way practitioner-client relationship is not regulated by customary socio-cultural realities of the communities, such as of collective responsibility, but is managed by unforeseen professional ethics which can be contested and validated within the court of law, at times devoid of context. Such professional practices shape the rules of engagement between the practitioners and the client and support the dominating and universalistic Eurocentric worldviews thus maintaining the traditional power relations of client and practitioners and alienate clients from their social and human relationships.

The ethical codes of practice are so entrenched in Eurocentric practices and traditions that emphasize objective and neutral professionalism. While social justice and respect for diversity are some of social work and psychology values, sharing ones political or religious affiliation with a client is regarded unethical. For example, starting a therapeutic session with a shared prayer can be construed as violation of ethical professional code. Practitioners are expected to be value free which is not a true reflection of the social reality of practitioners whose social existence and identity is embedded in the African-Centred ideology. African aesthetics and spirituality is discouraged and labelled as 'boundary crossing' which goes against African ontology which priorities the interconnectedness of the relationship of the individual with society and nature. Creation of interpretation of what Dixon el al (2010) call the 'Africana social reality' is impaired and the practice of psychology and social work becomes decentralised from the persons it purport to serve even at an individual level. When a person enters the therapy session he is stripped of his asserts such as faith and religion. The therapy session can easily alienate the client who has certain expectations based on his sociocultural and lived experience on what is 'normal' process in a helping relationship.

\section{Client's Rights to Self-Determination and Individuality}

In social work practice; self-determination means respecting and facilitating the ability of the client to make his or her own life choices and decisions (NASW Code of Ethics, 1996). Self-determination can also be seen as based in individualistic societies' valuation of self-determination as essential for adult functioning and the encouragement of independence rather than group interdependence (Dei, 1994). This value is particularly strong in the USA, the most individualistic culture in the world, according to Hofstede's (1980) study of world cultures. Despite self-determination as proclaimed by professional bodies as universal, there are important differences and challenges in its cross-cultural application. In African and traditional cultures, more emphasis is placed on collective rather than on individual interests, and on the achievement of individual fulfilment via group means (Hutchison, 1987). The whole of existence from birth to death is organically embodied in a series of associations, and life appears to have its full value only in these close ties (Healy, 2007). Traditions of mutuality and solidarity are prevalent within communities that uphold the African worldview (Dei, 2004). Africans, historically have been socialised to define themselves by their social obligations to the wider society (Mbiti, 1982 cited in Dei, 1994). As a number of commentators have pointed out, this does not mean that there is no independent thinking and action in African societies but it always has to be within the norms of the community (Mbugua, 2008).

A decision affecting an individual is made in consultation with others. No man is an Ireland. The traditional African; respect for authority of elderly persons, for their wisdom, knowledge of community affairs, and "closeness" to the ancestors (Bascom, 1942 cited in Dei, 1994). Many Africans believe old age comes with wisdom and understanding of the world. It was the duty of the aged to instruct the youth in a socially responsible manner and the latter's duty to respect the knowledge of the elders (Dei, 1994). These communities view the provisions of the South African Children's Act 38 of 2005 on the rights to termination of pregnancy by a twelve (12) year old child without a parent's consent as taboo. The role of the counsellors in pre- and post-termination counselling can be in direct conflict with traditional African solidarity 
especially because the ethical code of conducts prohibits counsellors from disclosing such information. Non-disclosure can affect socialization and support the youth can get from peers and other responsible adults. This pose as a challenge to the client's wellbeing who might be isolated from what Dei (1994) call the indigenous mutual self-help group as well as kin and non-kin social groups.

Within the cosmological perspective of the African-centered worldview, everything is connected and interdependent (Graham, 1999). The maintenance of harmonious social relationships supports the development of positive self-esteem and social competence (ibid). Social problems and human dysfunction arise when people become alienated and disconnected from their independent human relationships. This philosophical assumption transmits to the psyche a sense of belonging to the collective and of being part of the whole (Graham, 1999). From this assumption of collective identity follows the emphasis on human similarities or commonalities rather than on individual differences (Asante, 1988). Self-determination is an inappropriate concept for use in addressing individual problems in Africa because it assumes concepts of individuality which are not applicable in an African culture or society (Silvawe, 1995 cited in Healy, 2007). Silyawe recommends a value of group determination rather than self-determination (ibid). Social challenges are viewed as a collective responsibility rather than an individual responsibility. This premise thus relieve individuals with social challenges any stigma that might be attached to their failures. This worldview regards children as the collective responsibility of the community (Graham, 1999). The African proverb "It takes a village to raise a child" expresses the view that child rearing is a collective responsibility, rather than falling on individual nuclear families. Children are highly valued in general, as being of the community, and they therefore cannot be deemed illegitimate (Suda, 1997 cited in Graham, 1999).

The success of an individual is measured not by her/his material wealth, but the social networks and the contributions he/she has made on others in the community. Individual identity emerges from communion with others (Osagie, 1980 cited in Dei, 1994). The responsibility of citizenry included providing communal forms of labour at any time when called upon by the traditional polity, as well as making compulsory financial and nonfinancial contributions to assist bereaved families in burying the dead (Dei, 1994). Death, burial and bereavement are community affairs, and the close examination of the conduct of funeral ceremonies illustrate both collective responsibility and information sharing within traditional African communities (ibid). Death in the family must be communicated to the whole community through the traditional polity, and it was mandatory that all set aside their individual tasks and responsibilities to partake in observing the final rites of the dead (ibid). Giving gifts or money to the destitute clients, which symbolizes the African communal values of mutual responsibility and reciprocity can lead to disciplinary actions for practitioners. The universal code of ethics discourages and controls the communal values of mutual responsibility and reciprocity between the clientpractitioner by delimitating the boundaries of the relationship and controlling adherence to the prescribed forms of behaviour using professional bodies and legal institutions. The practitioner often remain in a dilemma as their discretion can cost them their jobs but at the same time they might loose their credibility within the community they serve because they do not to meet the expected needs of the community. To many Africans, the dichotomy is not between the individual and community, but between the competitive individual isolated from his or her community and the cooperative individual enriched by the community (Dei, 1994:12).

\section{Informed Consent}

There is little doubt that issues surrounding confidentiality and privacy are among some of the most difficult in social work and psychological practices (Congress and McAuliffe, 2006). Defining what is meant by the term 'confidentiality', and just how far it should be upheld in situations where there is risk to self or others that may justify disclosure of information, is an on-going concern (ibid). The value of confidentiality receives much more focus in countries with a strong Anglo-Saxon emphasis on individual rights such as Australia and the United States (Healy, 2005). As Healy (2001) indicates, developing countries may value a more collective approach to problem solving, by consulting extended family or village elders, rather than protecting an individual's right to privacy and confidentiality. Within indigenous settings, cultural protocols of engagement are all important in order to establish relationships (Morelli \& Mataira, 2010).

The crisis of partner notification and medical status disclosures that is associated with HIV and AIDS brought new complications in the confidentiality discourse. For Africans, the principle of life as the greatest gift to humans, respect for life, love for life and procreation, and an understanding of the existence of the person in the strong living chain of ancestors and the lives which are to come in the future (Chummar, 2008). Ethically, practitioners have a responsibility and a duty to keep their clients' confidentiality. This means that the practitioner may not disclose any information revealed by a client without the full knowledge of the client, purpose of which, is to allow the patient to feel free to make full and frank disclosure of information to the practitioner with the knowledge that the physician will protect the confidential nature 
of the information in respect to the autonomy of the patient (Chummar, 2008). Confidentiality might be adhered to in the expense of an HIV negative partner who is having an unprotected sex with the HIV positive client who might not yet be ready to disclose his/her medical status. The value of respect and love for human life might be greatly compromised while the client's right to confidentiality is respected.

\section{Conclusion}

This article has highlighted the ethical implications of practising social work and psychology in indigenous societies. It has sets out to contribute to the transformative political agenda by treating human service practice contestations not as encumbrances, but as the building blocks in the realisation and advocating for the locally relevant practices. As scholars, the need exist to fully engage and fully develop the African Code of Professional Ethics not only for the people of Africa, but to give Africa its rightful place in the production of local and universal knowledge. As Africa continues to celebrate African Renaissance and African universities continue to commit to African Scholarship, it is worrying that current professional codes of ethics for social work and psychology are still indistinguishable from their counterparts in Western countries. Mamdani (1997) cited in Seepe (2004) said, "Excellence has to be contextualised and knowledge made relevant. Shed this mimicry of the West that continues to parade as universal excellence and to take on the challenge to produce knowledge that takes the African condition as its central problem.

The African condition is historical and not biological." We, the African scholars and practitioners therefore have to face and indeed overcome the penalties of colonial history. But most importantly, we have to face the responsibility of being practitioners servicing indigenous communities. These responsibilities are ethical, moral, intellectual and inspirational and they are served not only by adapting our training and practices to the social structure and the cultural environment of Africa but also producing professional knowledge and practices that put African condition and the African identity at the centre of any intervention. Scholars like Ngugi wa Thiong'o (2003) have been calling for decolonisation of the mind and unlearning of the dominant ideologies, values and attitudes that perpetuate the agenda of the colonial regime. Serious attempts need to be made to adopt a more inclusive epistemology that is reflective of the culture, practice and lived-experiences of Africans within the African continent. Social workers and psychologists must not pay lip service to some of the ethical codes of conduct such as those relating to competence and ensuring that the best interest of the client is served, but should continuously critically appraise their relevance within their professional practice and be proactive agents of social change and bring about social justice.

\section{References}

Allan, A. (2001). The Law for Psychotherapists and Counsellors. Inter-Ed Publishers, Somerset West, South Africa.

American Psychiatry Association (2000). Diagnostic and Statistical Manual of Mental Disorders (4th Edition). Text Revision, American Psychiatric Association, Washington, DC.

Asante, M. (1988). Afrocentricity: The Theory of Social Change. Trenton, NJ: Africa World Press.

Asante, M. (1990). Kemet, Afrocentricity and Knowledge. Trenton, N J: AfricaWorld Press.

Askeland, GA and Payne, M (2006). Social Work Education's Cultural Hegemony. International Social Work, 49(6), 731-743

Berk, L. E. (1998). Development Through the Lifespan. U.S.A. Allyn \& Bacon.

Chummar, P (2008). HIVIAIDS in Africa: A Bioethical Hard Blow to Human Dignity and Human Rights. Proceedings of the International Conference on Bio-Ethics, 12-14 August 2008, Egerton University. http://unesdoc.unesco.org/images/0018/001841/184159e.pdf. Accessed in September 2012

Congress, E \& McAuliffe, D (2006). Social work ethics: Professional codes in Australia and the United State. International Social Work, 49, 151-164

Dei Sefa, GJ (1994). Afrocentricity: A Cornerstone of Pedagogy. Anthropology \& Education Quarterly, 25(1), 3-28.

Dixon, VJ, Nichols, EJ, \& Nobles,W (2010). A Genealogy of the Worldview Framework in African-Centered Psychology: Setting the Foundation. The Journal of Pan African Studies, 3(8), 114-130.

Graham, MJ (1999). The African-Centered Worldview: Toward a Paradigm for Social Work. Journal of Black Studies, 30 (1), $103-122$.

Gray M (2005) Dilemmas of International Social Work: Paradoxical Processes in Indigenisation, Universalism and Imperialism. International Journal of Social Welfare, 14, 231-245.

Gray, M., \& Fook, J. (2004). The quest for a Universal Social Work: Some Issues and Implications. Social Work Education, 23(5), 625644.

Healy, L. M. (2007). Universalism and Cultural Relativism in Social Work Ethics. International Social Work, 50, 11-26.

Hugman, R (2008). Ethics in a World of Difference. Ethics and Social Welfare, 2(2), 118-132

Hugman, R. (2005). Looking Back: The View from Here. British Journal of Social Work, 35, 609-620.

Hugman, R, Moosa, M, \& Moyo, OM. (2010). Towards a Borderless Social Work: Reconsidering Notions of International Social Work. 
International Social Work, 53(5), 629-643.

International Federation of Social Work (2000). Definition of Social Work. Retrieved September 2012 from: http://www.ifsw. org/en/p38000208.html.

Mbiti, J (1969). African Religions and Philosophy. Nairobi: Heinemann

Mbugua (2008). HIVIAIDS in Africa: A Bioethical Hard Blow to Human Dignity and Human Rights. Proceedings of the International Conference on Bio-Ethics, 12-14 August 2008, Egerton University. http://unesdoc.unesco.org/images/0018/001841/184159e.pdf. Accessed in September 2012

Moldovan, V \& Moyo, O (2007). Contradictions in the ideologies of helping: Examples from Zimbabwe and Moldova. International Social Work 50(4): 461-472.

Morelli, PT and Mataira, PJ (2010). Indigenizing Evaluation Research: A long-Awaited Paradigm Shift. Journal of Indigenous Voices in Social Work, I1(2), 1-12.

NASW (1996). The Code of Ethics. Accessed September 2012. http://www.sp2.upenn.edu/docs/resources/nasw_code_of_ethics.pdf.

Nelson, PJM (2007). An Easy Introduction to Egan's Skilled Helper Solution Focused Counselling Approach. http://www. org/downloads/PDFs/SFP-EasylntroToEgan.pdf. Accessed in September 2012.

Painter, D, Terre Blanche, M \& Henderson, J (2006). Critical Psychology in South Africa: Histories, Themes and Prospects. Annual Review of Critical Psychology, 5, 221-235.

Payne, M., \& Askeland, G. A. (2008). Globalization and International Social Work. Postmodern Change and Challenge. Aldershot: Ashgate Publishing Company.

Pettifor, J.L. \& Ferrero, A. (2012) Ethical Dilemmas, Cultural Differences, and the Globalization of Psychology, in M.M. Leach, M.J. Stevens, G. Lindsay, A. Ferrero \& Y. Korkut, The Oxford Handbook of International Psychological Ethics, Oxford University Press, New York.

Seepe, S (2004). Towards an African Identity of Higher Education. Vista university and Skotaville media, Pretoria.

Sewpaul, V. (2006). The Global-local Dialectic: Challenges for African Scholarship and Social Work in a Post-colonial World. British Journal of Social Work, 36, 419-434.

Schiele, J. (1994). Afrocentricity as an Alternative Worldview for Equality. Journal of Progressive Human Services,5, 5-25.

Schiele, J. (1997). The Contour and Meaning of Afrocentric Social Work. Journal of Black Studies, 27, 800-819.

Shockley, KG \& Frederick RM. (2010). Journal of Black Studies, 40(6), 1212-1233 10.1177/0021934708325517 http://jbs.sagepub.com hosted at http://online.sagepub.com Accessed in February 15, 2012

Solas, J (2008). What Kind of Social Justice does Social Work Seek? International Social Work, 51, 813-822.

Staniforth, B, Fouché, C \& O'Brien, M (2011). Still Doing What We Do: Defining Social Work in the 21st Century. Journal of Social Work, 11, 191-208

Tedla, E (1995). Sankofa: African Thought and education. Pieter Lang, New York.

Shockley, KG \& Frederick RM (2010). Journal of Black Studies, 40(6), 1212-1233. http://online.sagepub.com. Accessed on the 15th of February 2012.

Van Vlaenderen, H \& Neves, D (2004). Participatory Action Research and Local Knowledge in Community Contexts. In D. Hook, N.J. Mkhize; P. Kiguwa \& A. Collins (2004). Critcal Psychology, 445-464, UCT Press, Cape Town. 